\title{
Los enterramientos de la Edad del Bronce medio en la Península Ibérica: aproximación a su origen y paralelismos
}

\author{
Elena Sanz del Cerro
}

Desde que los hermanos Siret (1890) descubrieron y analizaron el yacimiento de El Argar (Antas, Almería), y quedó estructurada la cultura homónima, son muchos los investigadores que se han ocupado de las prácticas funerarias realizadas en la Península lbérica a lo largo del ámbito cronocultural genéricamente denominado Edad del Bronce Medio, pero pocos de ellos se han preocupado realmente de estudiar sus origenes y paralelos. No obstante, se han ido formando dos líneas de investigación:

Aquella que considera la procedencia foránea de la cultura "argárica", buscando precisamente la mayoría de los prehistoriadores que siguen esta corriente sus orígenes en algún punto del Mediterráneo Oriental (bien sea a través de una colonización, una invasión o una aculturación), tal como han opinado, entre otros, J. Martínez Santaolalla (1947), B. Blance (1964) o en un primer momento H. Schubart (1976).

Y la que se decanta por un desarrollo autóctono fruto de una dinámica y de una evolución local, por la que se ha manifestado defensor $P$. Bosch Gimpera, cuyo pensamiento evolucionó de apoyar una invasión exterior -1932 - a hacerse partidario de la evolución propia -1954-, al igual que le sucedió a $H$. Schubart (1986), que dejó de considerar la participación de influencias mediterráneo-orientales como origen de esta cultura. Otros investigadores que podemos destacar en esta línea han sido J. de Mata Carriazo (1963), V. Lull (1083) y A. Gilman (1976).

Partiendo de esta discusión, vamos a intentar ofrecer una visión general y resumen de los resultados obtenidos en el análisis que ya llevamos 
a cabo en otro lugar ${ }^{1}$, para comprobar si efectivamente se encuentran raices, al menos en lo que respecta al ritual funerario, en el entorno del Mediterráneo Oriental.

Para ello hemos utilizado una base de datos elaborada por nosotros con necrópolis y enterramientos peninsulares clasificados como pertenecientes a la Edad del Bronce Medio (tabla 1), así como una selección de sepulturas individualizadas localizadas en la cuenca del Mediterráneo Oriental, que por su ubicación cronológica, tipología de enterramiento y los aspectos rituales que las rodean, consideramos que nos podían permitir intentar la búsqueda de paralelos y relaciones con las incluidas en la Peninsula lbérica. Es el caso de Anatolia, Bulgaria y Grecia, tanto insular (Islas Cícladas, Keos, Lesbos y Creta) como continental (tabla 2). En total hemos podido contar con un corpus de más de 1.700 tumbas, todas fruto de un mismo ritual de inhumación: el individual (llegando a contener hasta cuatro cuerpos), realizado en el interior del área habitada o cerca de ella.

Asimismo, ateniéndonos a sus caracteristicas formales y constructivas, se han podido agrupar todas en ocho tipos diferentes: de cámara, cistas, covachas, fosas, tumbas construidas con lajas, de mampostería, "pithoi" o recipientes cerámicos y de túmulo, resultado de un criterio unificador para todo el área de estudio, aunque las sepulturas de cámara, como tales, se encuentran ausentes en la Península.

Sin embargo, debemos tener en cuenta la irregularidad del registro arqueológico, en el que la necrópolis de El Argar continúa siendo la mayor documentada, no sólo en nuestro territorio sino también fuera de él, lo que influye negativamente en el momento de llevar a cabo cualquier tipo de análisis comparativo en este contexto, en el que la desaparición del ritual colectivo de enterramiento supone la cristalización del individualismo en la ideología funeraria, a la vez que los propios asentamientos son utilizados para sus prácticas, mostrando la existencia de una relación directa entre el mundo de los vivos y el de los muertos, un nuevo sistema ideológico sobre el que se fundamenta la sociedad del II milenio.

Por lo que respecta a nuestra Península, también debemos mencionar que precisamente no se caracteriza por una unidad cultural en el Bronce Medio, sino que contamos al menos con cuatro grandes bloques culturales hasta ahora reconocidos. Sus diferencias se concretan en el plano religioso, tanto en una desigual adaptación o predilección de unos

1 Concretamente en nuestra Tesis Doctoral titulada: Enterramientos del II milenio en la Península Ibérica: Problemática de su origen y relaciones (Madrid 1993, inédita). 
sistemas de enterramiento frente a otros, como de ofrendas funerarias, agrupadas por nosotros en cuanto ítems: vasijas cerámicas, armas o útiles de metal, adornos y "otros objetos". Así, el análisis microespacial llevado a cabo respecto al continente y al contenido de las tumbas peninsulares nos ha permitido matizar lo siguiente en cada uno de ellos:

\section{BRONCE ARGÁRICO}

A tenor de nuestros datos, y utilizando las unidades administrativas actuales, contamos con enterramientos en las provincias de Almería, Granada, Jaén, Murcia y parte de Alicante. Sin embargo, la caracterización de una cultura arqueológica implica, tanto la presencia reiterada de ciertos restos materiales como de un contenido esencial que la diferencia de conjuntos culturales anteriores y posteriores. En este sentido, la "norma argárica" responde a un concreto patrón de asentamiento, con determinadas formas constructivas en los poblados, ciertos artefactos cerámicos y metálicos y una asociación hábitat-necrópolis, en la que los ajuares funerarios muestran sin duda una riqueza desigual.

Precisamente en el estudio de las sepulturas argáricas es donde se ha tenido que concentrar gran parte de las investigaciones. El análisis realizado por nosotros de las provincias catalogadas nos ha permitido agruparlas en función de los patrones de comportamiento distinto: por un lado Almería y Murcia, que muestran un claro predominio por el uso de los "pithoi» como sistema de enterramiento, $y$, por el otro, el resto de las provincias, que utilizaron preferentemente las cistas. Sin embargo, debemos recordar que Almeria y Murcia constituyen las dos únicas zonas que destacan por incluir «marco-necrópolis": la de El Argar (con 559 tumbas catalogadas) y la de El Oficio (aunque de las 200 sepulturas que mencionan los Siret sólo hemos podido individualizar 14) en Almería y la de La Bastida de Totana en Murcia (con 102 enterramientos). Estos yacimientos se corresponden con poblados que podemos considerar verdaderos centros políticos-sociales.

Asimismo, debemos señalar que el comportamiento «argárico» funerario de Alicante sólo nos ha sido posible localizarlo en dos necrópolis: Las Laderas del Castillo (Callosa del Segura) y San Antón (Orihuela), mientras los demás yacimientos alicantinos catalogados se incluyen en la cultura del Bronce Valenciano, presentando una mayor pobreza de ofrendas funerarias, sobre todo de armamento metálico.

En esta dinámica tenemos que señalar la "personalidad» del altiplano de Jumilla-Yecla (Murcia), más cercana al Bronce Valenciano que al 
argárico, lo que refleja la dificultad de delimitar exactamente las fronteras entre ellos y el Bronce Manchego.

La conducta respecto a los ajuares que incluyen las tumbas argáricas también nos permite encontrar ciertas diferencias en los dos grupos establecidos en función del tipo de sepultura. Así, Granada y Jaén muestran un predominio general de ofrendas exclusivamente cerámicas, aunque en esta última los ajuares tienden a ser más pobres, no llegando ninguna tumba a contener los cuatro "ítems" en que hemos agrupado las ofrendas. Por tanto, y aunque tengamos en cuenta que la cantidad de enterramientos jienenses es menor, el resultado no hace sino reflejar el distanciamiento con respecto al foco almeriense.

En relación con Almería y Murcia, no hay duda que su patrón de conducta nos permite diferenciarlas del resto de las provincias por su preferencia tipológica. No parece ocurrir así con los ajuares, ya que las tumbas almerienses son las únicas que incluyen todas las combinaciones posibles que se pueden establecer con los cuatro grupos de ofrendas establecidos, predominando las asociaciones de vasijas cerámicas, armas/útiles de metal y adornos; cerámica y armas/útiles metálicos; cerámica y adornos, adornos o bien sólo vasos cerámicos. En Murcia la costumbre parece inclinada más hacia una ausencia total de ajuar (situación que sólo aparece en una pequeña cantidad de enterramientos almerienses), aunque también se encuentra una proporción importante de tumbas con sólo ofrendas cerámicas o con vasijas y armas/útiles de metal.

Así pues, aunque esta provincia se muestra más próxima al comportamiento funerario de Almería, el resultado refleja que precisamente en esta última hallamos más acentuada la diferenciación entre "pobreza" y "riqueza" (bajo este concepto se ha considerado tanto la cantidad de objetos como su calidad, determinada por materiales como el metal o el marfil), existiendo además una mayor proporción de sepulturas "ricas" que en otros lugares. En definitiva, consideramos que la «riqueza» debió quedar concentrada en pocas manos, manifestándose en el ritual funerario tanto en una determinada tipología como en la calidad y la cantidad de ofrendas, en las que destaca el carácter "metálico" como elementos diferenciador. Almería es el máximo exponente de ello, a la vez que concentra una parte importante de los hallazgos de la Península.

\section{BRONCE DEL SUROESTE}

Al menos forman parte de este complejo cultural las provincias de Huelva, Sevilla y las regiones portuguesas del Algarve y del Alto y Bajo 
Alentejo. Se caracterizan por mostrar una especial inclinación, en función de los datos obtenidos, por enterrarse en cistas, especialmente en Huelva y en el Alto Alentejo, donde constituyen el único sistema utilizado. Las fosas se corresponden con el segundo tipo más empleado en esta área cultural, en la que incluso una sola necrópolis concentra la mayoría de las tumbas (nos referimos a la de El Becerrero, en Huelva).

Los ritos funerarios de esta cultura manifiestan la necesidad de reconocer en ella una verdadera personalidad diferenciándola de la argárica, aunque las dos tengan un remoto origen común.

Entre las costumbres funerarias que constituyen un fenómeno específico se encuentra el "culto al cráneo", el ejemplo más significativo se corresponden con una cista de Alcaria (Algarve), en la que el cráneo se introdujo en un compartimento realizado con dos lajas. En otros casos aparece aislado en una tumba o acompañado de otros huesos, ordinariamente los de mayor tamaño. Este especial tratamiento o rito lo encontramos también registrado en sepulturas de Anatolia durante el III milenio a.C., especialmente en una urna de Babaköy, cuyos dos esqueletos presentaban los cráneos separados del cuerpo y colocados uno contra el otro, y en una fosa de Troya I, en la que la cabeza del único individuo inhumado se protegió con dos losas, dispuestas una a cada lado y otra horizontal, siendo este último hallazgo muy similar al de Alcaria.

Todo ello nos lleva a considerar la importancia que debieron conceder a esta parte del cuerpo, quizás como símbolo de la memoria de un antepasado, aunque no se puede afirmar que fuera una práctica generalizada en ninguno de los dos extremos del Mediterráneo.

Otra peculiaridad es que, tanto en la zona portuguesa como en la española, se ha comprobado la existencia de gran parte de enterramientos que no contienen restos óseos, estando en unos casos la tumba completamente vacía y en otros con ofrendas, por lo que han recibido la consideración de "cenotafios". Fuera de la Península también hemos localizado algunas sepulturas vacías en Grecia Continental, concretamente en la Argólida (Asine, Micenas) y en Atica (Aghios Kosmas).

Dentro del ámbito meridional de la Peninsula, debemos mencionar los aún escasos hallazgos funerarios detectados en las provincias de Málaga y de Cádiz, de cistas y alguna fosa respecto a la primera y, más concretamente, de fosas respecto a la segunda. Ambas quizás se pueden interpretar, desde el punto de vista de la tipología utilizada, como jalones que avanzan desde el área argárica antes de entrar en el horizonte de cistas del Suroeste, fruto de una irradiación argárica, coincidiendo en 
parte con la expansión de esta cultura ${ }^{2}$, aunque habrá que esperar a nuevas investigaciones para conocer la importancia de la influencia argárica en la Andalucía Occidental.

Respecto a los ajuares utilizados en esta área cultural, se manifiesta la inclinación de sus sepulturas, dentro de la "pobreza» que les caracteriza, a contener sólo ofrendas de recipientes cerámicos e incluso a no incluir ningún objeto, siendo el Bajo Alentejo la región portuguesa que destaca no sólo por presentar la mayor concentración de tumbas, sino también por predominar en ellas la ausencia de ajuar. Sin embargo, al menos en cada provincia o región euroccidental se encuentra catalogado un enterramiento con alguna ofrenda metálica, en su mayoria armas (puntas de flecha, cuchillos-puñales, hacha, espada y alabarda), en especial una fosa sevillana, la única localizada en el Suroeste que presenta una espada y una alabarda, acompañadas además de un puñal, un vaso cerámico y ofrendas de alimento. Esta "riqueza» sólo es comparable en todo el grupo a una cista del Alto Alentejo (con dos cuchillos-puñales, un punzón y cuatro vasijas).

No obstante, debemos considerar la gran escasez de objetos metálicos en proporción con la cantidad de enterramientos catalogados. Quizás el metal no lo "desperdiciaban" en realizar otro tipo de ofrendas (como los adornos) que no fueran las armas. Los objetos suntuarios metálicos parecen dejar paso al armamento, verdadero elemento diferenciador (como escaso) de riqueza o poder.

\section{BRONCE VALENCIANO}

Encontramos sepulturas de este grupo cultural en las provincias de Alicante, Castellón y Valencia, que destacan por presentar cada una un comportamiento funerario en cierta manera diferente. Asi, Alicante se muestra tipológicamente más cercana a las costumbres "argáricas", al recogerse su preferencia por enterrarse en cistas, destacando en menor grado la utilización de covachas, fosas y "pithoi", mientras que en Castellón únicamente hemos registrado el sistema de las fosas, y en Valencia encontramos cistas, fosas y urnas, aunque destacan las covachas. Por tanto, los "pithoi" constituyen un tipo de enterramiento muy poco utilizado en este grupo, que incluso llega a realizar algunas de las inhumaciones en el interior de cuevas, frente a lo que ocurren en otras

z Tal como afirman J. L. Escacena y N. Berriatua (1985: 238). 
áreas peninsulares. No obstante, fuera de la Península, podemos mencionar por ejemplo a Creta, que desde el Minoico Medio II B construye cámaras excavadas en la roca, las cuales podrian ser el resultado de la antigua tradición minoica de enterarse en cuevas naturales (POYATO, C. 1988: 23).

El comportamiento en relación con las ofrendas es también algo diferente en cada provincia. Así, se observa una degradación en la calidad de las ofrendas a medida que nos alejamos del foco argárico. Por ello, ninguna de las tres fosas catalogadas en Castellón incluye metal, ciñéndose sus ofrendas a los vasos cerámicos y a un molino de mano. La situación en Valencia se manifiesta algo más evolucionada, ya que a pesar de que cinco de sus once tumbas no contienen ajuar, al menos se han localizado dos con metal: una covacha y la única urna de la provincia. Precisamente este sistema de enterramiento, típicamente «argárico", se asocia con el único objeto clasificado como arma.

Por el contrario, en Alicante es donde hemos recogido la mayor cantidad de tumbas y de ofrendas metálicas, la mayoria adornos, llegando en algunos casos a ser de oro, aunque se trata de objetos únicos, asociados a covachas y a cistas (especialmente en el Cabezo Redondo de Villena). La "riqueza" de estas sepulturas la constituye la calidad del metal empleado, puesto que no se incluyeron otras ofrendas.

Las armas también forman un bien escaso. Sólo nueve tumbas alicantinas presentan alguna, normalmente un cuchillo-puñal, identificándose cuatro de ellas como típicamente "valencianas", ya que el resto se ha localizado en el yacimiento de Las Laderas del Castillo (donde se encuentra el único ejemplo de alabarda).

Por tanto, Alicante se constituye en la provincia con mayor "riqueza" funeraria de todo el grupo cultural, destacando sobre todo el Cabezo Redondo, quizás porque de su necrópolis hemos obtenido información de 19 enterramientos, constituyendo el conjunto más numeroso no sólo de la provincia sino de todo el Bronce Valenciano.

De cualquier manera, las gentes de esta área cultural parecen mostrarse poco innovadores, siendo un limitado número el que acepta los elementos nuevos.

\section{BRONCE DE LA MANCHA}

Contamos con sepulturas de al menos tres de sus diferente facies: "Castellones" o cerros, "Motillas" y "Fondos de Cabaña". La primera facies la tenemos representada en la provincia de Ciudad Real y en la 
de Toledo, mientras que la segunda también aparece en Ciudad Real y la tercera en Guadalajara. Tipológicamente muestran una cierta diversidad en la elección del sistema de inhumación, ya que en Ciudad Real llegan a utilizar sobre todo una "variación" del tipo de cista: la tumba de “lajas» (encontrándose según nuestros datos únicamente, además de en esta provincia, en el Algarve portugués).

Le sigue en abundancia la sepultura de mampostería, la de "pithos", de fosa, así como una covacha. Por el contrario, en Guadalajara parece utilizarse sólo los enterramientos en fosas y en "pithoi" (localizados además en el interior de "fondos de cabaña", cuando la "norma" parece inclinarse hacia la construcción de casas de planta aproximadamente rectangular), mientras que en Toledo se ha recogido exclusivamente este último tipo de inhumación. En este sentido, no debemos olvidar que ambas zonas se encuentran por el momento simbolizadas respectivamente por un único yacimiento con necrópolis: la Loma del Lomo (Cogolludo, Guadalajara) y el Cerro del Obispo (Castillo de Bayuela, Toledo).

Respecto a la provincia de Madrid, los escasos enterramientos de los que nos podemos hacer eco hasta ahora se encuentran localizados en dos tipos de asentamiento: en "fondos de cabaña" (fosas y "pithoi») y en cuevas, aunque la ausencia general de una individualización clara del contenido de cada sepultura determinó en su momento que no se incluyera en nuestra base de datos, al igual que ha sucedido a yacimientos como la cueva de Segobriga (Cuenca), y ya en la periferia a Los Tolmos de Caracena, en Soria (un asentamiento del Bronce Medio Meseteño) o la necrópolis de Villalmanzo, en Burgos (de cistas y "pithoi»).

En definitiva, no sólo tenemos recogido en el Bronce de La Mancha un modelo de tumba diferente al resto de los tipos peninsulares: el de lajas (aunque algunas de las necrópolis cicládicas presentan estructuras de lajas o de mampostería que rodean a «pithoi», además de sus cistas tipo «standard", realizadas con lajas de piedra), sino que también uno de los sistemas característicos del Bronce Argárico, el correspondiente a las cistas, no llega a localizarse en ninguna de las tres provincias mencionadas.

Otra de las peculiaridades de este bloque cultural es que precisamente incluye un yacimiento que concentra la mayoría de las tumbas: el Cerro de La Encantada (Granátula de Calatrava, Ciudad Real), al igual que sucede con Almería, Murcia o Huelva (en relación con la necrópolis de El Becerrero, en Almonáster).

El hallazgo de enterramientos realizados con "lajas" de piedras nos lleva a considerar que nos encontramos ante una variante local de la "cista", en función de la piedra disponible en el entorno. Así, en el caso 
del Cerro de La Encantada es la cuarcita, una roca muy dura para trabajarla en forma de losas del tipo utilizada en cistas como las de El Argar, casi todas de arenisca micácea, o las de Huelva, en pizarra, que eran también los materiales de que disponían en las proximidades del asentamiento.

Respecto al contenido mobiliar de las tumbas manchegas, la mayoría incluye algún tipo de ajugar, encontrando las más "ricas" en La Encantada, precisamente en la mayor necrópolis del grupo. Asimismo, salvo una fosa de Guadalajara con una punta de flecha metálica (un tipo de armamento poco usual como ofrenda funeraria), el resto de las armas se localiza en este gran yacimiento, concretamente son cuchillos-puñales, hallando en un solo caso una punta de flecha, que además corresponde a una sepultura de mampostería.

En realidad, los ajuares más abundantes en Ciudad Real son los que incluyen recipientes cerámicos, destacando a continuación aquellos denominados "otros objetos". Estos últimos caracterizan también a las provincias de Guadalajara y Toledo. Las ofrendas de alimento constituyen el tipo de ajuar más abundante dentro de esta categoría.

Por tanto, el acceso al metal se muestra muy restringido en esta área cultural, incluyendo otra clase de objetos funerarios de más fácil «adquisición».

El resto de la Península, salvo algún hallazgo aislado de "pithoi» y de cistas de lajas (como la mencionada necrópolis de Villalmanzo, en Burgos), o sólo de cistas (por ejemplo, en Oña, Burgos), entre otros, parece encontrarse dentro de un sistema de adaptaciones residuales de la «norma argárica», en un contexto que se mantiene también inmerso en las tradiciontes anteriores.

Por lo que respecta a la situación general que se observa en el Mediterráneo Oriental, refleja grandes paralelismos con lo que ocurre en la Península, especialmente con el área del Sureste, ya que los tres sistemas de enterramiento considerados típicamente "argáricos" son los que aparecen en este ámbito (cistas, fosas y "pithoi»). Sin embargo, aunque la cantidad recogida de tumbas orientales varía en gran manera entre unos modelos y otros, las cistas son las más abundantes, seguidas de las fosas y de las urnas. No debemos olvidar que este último tipo aparece perfectamente representado en todo el Mediterráneo Oriental, a pesar de que sólo ocho han sido catalogados. Asimismo, las sepulturas de Cámara se encuentran también en Grecia continental, e incluso teóricamente proceden de allí, introduciéndose su uso en Creta durante el Minoico Reciente. En Grecia, tanto en su parte este (Argólida) como oeste, igualmente loca- 
lizamos túmulos desde el principio del Heládico Medio, e incluso, tal como refleja una de las estructuras tumulares de Leukas, en el Peloponeso (con la que $\mathrm{H}$. Schubart ya habia comparado los túmulos portugueses), es posible fecharlos en el Heládico Antiguo II (DICKINSON, O.T.P.K. 1977: 34). En su interior se realizaban inhumaciones en urnas y en cistas.

Es decir, observamos la introducción de un rito nuevo de enterramiento: la inhumación individual convirtiéndose en el II milenio en una práctica habitual a lo largo del Mediterráneo: desde Anatolia, Palestina, Bulgaria, ya en el III milenio, a Grecia continental e insular, sin olvidar a Italia, donde conocemos la existencia de necrópolis con inhumaciones individuales en urnas en Sicilia, en fosas en el norte de Italia o en fosas y cistas en el centro y sur de la península, aunque la información no llegue a ser suficientemente explícita.

No obstante, podemos agrupar todas las sepulturas recogidas de! Próximo Oriente y del Egeo en cinco grupos, de acuerdo con las diferentes respuestas que ofrecen e su ritual funerario: Anatolia y la isla de Lesbos, Bulgari, las Islas Cícladas, Grecia continental y Creta. Este último lugar es el grupo más conservador, ya que mantiene la inhumación "colectiva", tradicional en la isla, llegando a mostrar una tendencia progresiva hacia las inhumaciones múltiples en la transición entre el Bronce Medio y el Reciente, como son los «tholoi» y las Tumbas de Cámara.

En todas ellas encontramos cistas, fosas y urnas, así como algunas covachas en Creta (Minoico Reciente) y en Malthi-Dorion (Mesenia) y tumbas de lajas (como en Anatolia, predominando los enterramientos intramuros, salvo en Creta, donde aparentemente son las necrópolis extramuros, más o menos alejadas de los asentamientos, el tipo preponderante.

Respecto a las ofrendas que acompañaban el cadáver, aunque una cierta cantidad de ellos han sido catalogados sin ajuar, no constituyen la regla general. Las preferencias por zonas son las siguientes:

- ANATOLIA: Sólo 6 de las 26 tumbas individualizadas presentan ajuar, exclusivamente cerámico o unido con "otros objetos" (ninguno de metal), correspondiendo la mayoría de las sepulturas sin ofrendas a enterramientos infantiles colocados debajo del suelo de las casas. Esta situación, presente tambièn en la Península, nos indica que la población infantil, o al menos una parte de ella, poseía el derecho a enterrarse. El único objeto extraño a la Peninsula es un cuenco de mármol. Asimismo, las dos únicas tumbas catalogadas de la isla de Lesbos (urnas sin ajuar) no se diferencian ni en el continente ni en el contenido de las recogidas en Anatolia. 
- BULGARIA: Los recipientes cerámicos y los adornos de concha y de metal constituyen las ofrendas más características, entre las que sólo se localiza una placa de mármol como elemento diferenciador. Incluso encontramos aquí los cuerpos espolvoreados de ocre rojo, costumbre también presente en la Península lbérica, al menos en lo que respecta a la necrópolis de El Argar. Su uso se encuentra ya atestiguado desde muy antiguo, pudiendo "simbolizar" la vida o incluso tener virtudes apotropaicas.

- ISLAS CICLADAS: La mayoría contiene algún objeto como ajuar, concentrándose en Naxos las tumbas sin ofrendas. Preferentemente contienen vasijas cerámicas y cuentas de collar de piedra, concha o hueso, además de recipientes o ídolos de mármol y hojas de obsidiana, que constituyen los dos únicos tipos de objetos "diferentes", quizá más en función del material utilizado que de la ideologia que subyace en su inclusión como ofrendas.

La presencia de metal es escasa, empleándose únicamente con carácter funerario en las armas: dos espadas de Naxos, además de hachas, dagas y una punta de lanza (en Amorgos).

La sepultura de mayor "riqueza» corresponde a una fosa de Syros que contenía incluso tres dagas, destacando como peculiaridad la ausencia de restos óseos.

Asimismo, la escasez de objetos metálicos que se observa en los enterramientos registrados nos permite preguntarnos si se trata, tanto de la consecuencia de una información insuficiente como del resultado de la economía de estas gentes, dedicadas al parecer a la agricultura y a una actividad propia de marineros y comerciantes, por lo que el metal quedaria reservado para su utilización en el comercio, permaneciendo en poder de unos pocos privilegiados.

- gRECIA CONTINENTAL: Excepto una pequeña cantidad de tumbas sin ajuar (concretamente 22 del total de 678), predominan aquellas que incluyen exclusivamente vasos cerámicos, aunque algunas de ellas llegan a contener además "otros objetos" y algún adorno, mientras que sólo siete reúnen todos los grupos de ofrendas establecidas (cerámica, armas/útiles de metal, adornos y "otros objetos»).

El ajuar, salvo en la única sepultura catalogada de Fócida (con cuatro pendientes de oro y un cuchillo-puñal, entre otras ofrendas), sólo lo encontramos reflejado como contenido funerario en Micenas (Argólida), donde se localizan las tumbas más ricas y con mayor cantidad de armamento (destacando las espadas, además de cuchillos, lanzas, dagas o puntas de flecha), lo que demuestra que la excepcionalidad del yaci- 
miento no es sólo tipológica. El mármol y la obsidiana, así como la piedra utilizada en las paletas, constituyen materiales diferenciadores con respecto a la Península Ibérica, no así las ofrendas de alimento, las cuentas de collar de marfil, de hueso, los molinos de mano o los adornos de concha.

- CRETA: Todos los enterramientos catalogados incluyen algún objeto, destacando aquellos que presentan recipientes cerámicos, armas/útiles de metal y "otros objetos", aunque también podemos mencionar los que contienen tanto vasijas de cerámica y "otros objetos" como los cuatro "ítems" en que hemos dividido un ajuar.

La proporción de armas es muy alta en relación con la cantidad de tumbas clasificadas, sobre todo en las de Cámara. Sin embargo, si tenemos en cuenta que sólo en el área de Knossos se han localizado más de 200 sepulturas del Minoico Reciente, de las cuales únicamente 22 corresponden a enterramientos de "guerreros", el resultado nos indica que sólo unos privilegiados podian gozar de dicha categoría.

Los ajuares cretenses son los que material y tipológicamente se apartan de lo que ocurre en la Península (por ejemplo, las formas cerámicas, ciertos recipientes de bronce, navajas y espejos de bronce o piedras como la cornalina o la esteatita para la fabricación de adornos, que constituyen elementos propios de la isla), aunque el marfil también se encuentran presente en alguna sepultura.

Asimismo, por lo que respecta a cada sistema de enterramiento utilizado en los dos ámbitos del Mediterráneo podemos matizar lo siguiente:

- Las denominadas COVACHAS o hendiduras en la roca, bien naturales o artificiales, con una pequeña cámara y un corto "dromos" de entrada, encontramos algunos ejemplos en las necrópolis de Fuente Alamo, Lugarico Viejo y El Argar en Almería o en Castellón Alto en Granada. Todas ellas son parecidas a las denominadas "rock cut tombs" del Egeo y de Palestina.

- Las sepulturas de LAJAS y de MAMPOSTERIA, que también encontramos en el Mediterráneo Oriental (por ejemplo, en Ayia Irini, en Keos, se han localizado de este último tipo), se pueden considerar «variaciones" dentro de la tendencia a sustituir un tipo de tumba de mayor calidad e incluso dificultad para realizarlo como es la cista. El análisis de la "riqueza" de sus ajuares nos permite confirmar que realmente son más "pobres" en calidad y en cantidad de ofrendas que las cistas, que a su vez muestran una variación respecto al tamaño, llegando, como sucede a algunas de Fuente Alamo, a dimensiones "monumentales" e incluso con un "dromos", estructura que también distingue a algunas covachas 
artificiales de dicho yacimiento. Sin embargo, ciertas tumbas de mamposteria presentan una gran calidad de construcción (situación en la que se encuentran algunas sepulturas del Cerro de La Encantada, en Ciudad Real), por lo que nos preguntamos si esta dificultad no se podría considerar por sí misma un símbolo de "riqueza», ya que quizá supondría un esfuerzo e inversión de tiempo similar o incluso mayor al de la construcción de una cista por ejemplo onubense, realizada con un material como la pizarra, que permite con gran facilidad extraer losas.

- Sobre las FOSAS, aunque puedan parecer el tipo más sencillo de realizar $y$, por tanto, quizá destinadas a grupos de menores posibilidades económicas o sociales, contamos con algunas de carácter «monumental", tanto en la Península lbérica (tal como ocurre en los yacimientos granadinos del Cerro de la Virgen y de la Cuesta del Negro, aunque en necrópolis de la importancia de Fuente Alamo o El Oficio no hemos podido catalogar ninguna fosa) como fuera de ella. Un ejemplo son las «Shaft Graves" de Grecia continental, concretamente nos referimos a las "Tumbas Reales" de Micenas - Círculos A y B-, además de las fosas de Ayia Irini, en Keos. Estos enterramientos, a pesar de haberse clasificado como "fosas" (realmente casi todas las sepulturas lo son, ya que primero solian realizar un hoyo para introducir la tumba), su especial "arquitectura" y morfología hacen que sean muy diferentes de los simples agujeros excavados en el suelo, al tratarse de grandes fosas revestidas con un muro de mamposteria que soporta un alzado de postes cuya finalidad era sujetar una cubierta, llegando a ser de enterramiento múltiple.

- Respecto a los "CONTENEDORES" utilizados, éstos pueden ser de cerámica, de piedra (como los de El Oficio, en Almería, o los de Agia Triada -con escenas de la consagración-, en Creta) o de madera. Los ejemplares más antiguos del Mediterráneo Oriental realizados con esta última materia proceden del Círculo A de Micenas, un siglo antes de que hicieran acto de presencia en Creta. Quizás sean relacionables, en nuestra Península, con numerosas tumbas del yacimiento de la Terrera del Reloj, en Granada, cuyas paredes fueron revestidas de un encofrado de madera.

Esta distinción de materiales nos lleva a pensar si la madera o la piedra no constituirian por sí mismas un elemento diferenciador frente a la cerámica, más empleada en la construcción de "contenedores" y, por tanto, con un carácter menos selectivo.

En relación con estos últimos, podemos clasificarlos en dos tipos: aquellos que se denominan tradicionalmente "PITHOl» o urnas, y los que se conocen como "larnakes" o sarcófagos de cerámica, que evolucionaron desde una forma ovoide a convertirse en cajas rectangulares. Sin embargo, los "pithoi" los podemos identificar con el sistema de enterra- 
miento más antiguo, desarrollándose en el Mediterráneo Oriental ya en el III milenio a.C. En la Península parece que llega más tarde, convirtiéndose en el más utilizado y en el que incluye más cantidad y calidad de ofrendas, sin olvidar que en este comportamiento influye sobremanera la concentración de 535 urnas (de las 699 catalogadas en total) en dos yacimientos: El Argar, en Almería, y La Bastida de Totana, en Murcia.

Asimismo, tecnológicamente los "pithoi" también presentan diferencias, llegando a localizarse en el interior de túmulos, de cistas o de hendiduras en la roca, e incluso a rodearse de estructuras de mamposteria, que en el caso del Cerro de La Encantada (Ciudad Real), se adosaron a unos edificios de carácter ritual (tumbas 0001 y 0007), en uno de los cuales se localizó un altar de "cuernos de la consagración", que junto con el aparecido en El Oficio (Almería), nos permiten presumir que las relaciones con el Egeo no eran sólo «materiales». Estos templos, aunque en la Península no se hayan encontrado por el momento ejemplos semejantes, no hacen sino recordarnos las "capillas" de carácter funerario de Ayia Irini (tumba 1) en Keos (OVereEck, G. F. 1984) y el Templo Tumba de Knossos, un complejo funerario en el que se encontró también un altar de cuernos en la capilla de su planta superior. Concebido quizás como tumba para un solo individuo, se utilizó como necrópolis a lo largo del Minoico Reciente I y II.

Es decir, la utilización de contenedores cerámicos fue una costumbre bastante antigua en el Egeo y en el Próximo Oriente, disminuyendo su uso a partir del Bronce Medio, cuando en la Península lbérica se empezó a utilizar este sistema.

Normalmente aquí se dispusieron horizontalmente, aunque algunos fueron colocados de forma vertical, boca arriba, como sucede en las necrópolis almerienses de El Argar, El Picacho y Fuente Alamo, caracteristica que encontramos habitualmente en Creta. Igualmente podian tocarse sus bocas al colocarse dos de ellos (cada uno con un individuo) juntos, diferenciándose en el ajuar lo que pertenece a cada uno (como sucede a las tumbas 0617 y 0618 de El Argar), e incluso se rodeaban de circulos de piedra para individualizar aún más la sepultura. El mismo significado tendría el hecho de tapar la boca de la urna, aunque la máxima expresión de este deseo lo tendríamos en el hecho de introducir un "pithos" dentro de otro (tal como aparece documentado en el yacimiento de Fuente Alamo).

- Los TUMULOS, presentes, por tanto, en los dos extremos del Mediterráneo, llegaban a contener en su interior sepulturas de cistas, fosas y "pithoi", con la excepción de los únicos calificados por nosotros como tales, pertenecientes al Bajo Alentejo portugués, concretamente a 
la necrópolis de Atalaia, en la que se construyeron estructuras tumulares que cubrian al individuo dispuesto directamente sobre el suelo, sin incluirlo en otro sistema de enterramiento. No obstante, aunque en nuestra Península hayan sido catalogados en función del sistema de inhumación que contenían, los encontramos, asociados con cistas y fosas, en las necrópolis alicantinas del Cabezo Redondo y de Las Laderas del Castillo, presentando todos ofrendas, mientras que los "túmulos" de Atalaia o no contienen ajuar o incluye únicamente algún recipiente cerámico. En el Mediterráneo Oriental podemos contar con algunos ejemplos en Bulgaria y en Grecia continental, conteniendo estos últimos una clara "riqueza" de ofrendas, lo que permitiría identificar este modelo de enterramiento, al menos en esta zona, con un monumento funerario perteneciente a grupos o estratos sociales de un nivel parecido y seguramente alto, entre los que se podrían encontrar los gobernantes locales según la opinión de O.T.P.K. Dickinson (1977: 34).

Sin embargo, aunque en nuestro territorio no podamos ir tan lejos, en el sentido de que las ofrendas contenidas en las sepulturas clasificadas como "túmulos" no destacan precisamente por su "riqueza", como ocurre en Grecia continental, quizás podamos considerar la idea de buscar la diferenciación económica o social en el uso específico de la propia tipología del enterramiento, en definitiva, podría ser un indicador de riqueza o de diferenciación de grupo, siendo esto último el aspecto que podemos considerar en relación con el sistema alveolar de túmulos (debajo de los cuales también se realizaron enterramientos en cistas y en fosas), que es el mismo tipo de agrupación observando en las cistas onubenses y sevillanas, lo que podria mostrarse como la consecuencia del mantenimiento de la organización social en familias o en núcleos de parentesco.

Por tanto, encontramos en cada modelo especifico de enterramiento una variación o gradación respecto a la tecnología utilizada, tendente a individualizar y a remarcar la presencia de la tumba, cuya culminación pensamos que se encuentra en el uso de los "pithoi", no porque el grado de desarrollo de la alfarería permitiera que fuera menos trabajoso realizar un contenedor cerámico que por ejemplo una cista de losas (precisamente más utilizadas en zonas de abundancia de piedra, como la pizarra, material con el que se construyeron las cistas onubenses), sino porque sería la manera de individualizar o de encerrar más aún al cuerpo, sin contacto con la tierra, puesto que las cistas dejarían quizás algún resquicio entre sus locas, a no ser que estuvieran perfectamente trabadas entre ellas. En este sentido, no hay que olvidar que sellaban incluso la boca de la urna. Respecto al ajuar, se puede considerar propiedad del individuo y, como tal, presenta claras distinciones tanto en un tipo 
de tumba como en otro, llegando una cantidad importante de sepulturas a incluirlo en mayor o menor medida.

Otro aspecto a tener en cuenta en esta dinámica es la ausencia en la Península lbérica de gran cantidad de necrópolis en territorios donde curiosamente se encuentra constatada la existencia de poblaciones. Efectivamente, si analizamos la obra de V. Lull (1983), como compendio del área argárica, observamos que de 168 asentamientos que estudia, sólo 60 se identifican con el hallazgo de sepulturas. Por ello, nos preguntamos si esta circunstancia no es fruto de la casualidad, encontrándonos ante zonas nucleares a la que acudirian gentes de lugares próximos incluso a enterrarse, vinculados de alguna manera con estos núcleos más importantes, lo que podria explicar la presencia de grandes necrópolis en zonas como Almería (con los yacimientos) de El Argar y El Oficio, e incluso el de Fuente Alamo), Murcia (con La Bastida de Totana) o el Bajo Alentejo (Atalaia).

El Bronce de La Mancha presenta una situación semejante al área del Sureste. Así, de aproximadamente 200 asentamientos localizados entre las provincias de Albacete, Ciudad Real, Cuenca, Guadalajara, Madrid y Toledo, sólo alrededor de 50 presentan indicios o información más detallada de hallazgos funerarios, lo que nos sugiere que no todos los poblados tendrian "derecho" a utilizar este ritual para enterrar a sus gentes y, aunque asi fuera, suponemos que tampoco todos los habitantes gozarían de este privilegio.

Todas estas consideraciones nos llevan a plantearnos otro hecho: ¿Es posible que no todos los individuos tuvieran «derecho" a disponer de una tumba para enterrarse, con lo cual se enterrarian sólo aquellos que la sociedad lo permitiese? Esta diferenciación de "grupos" podría confirmar las teorias de V. Lull y Jordi Estévez (1986) acerca del comportamiento social de la cultura argárica, deducido del análisis de sus ajuares funerarios, en las que fijan el establecimiento de cinco categorias sociales, desde la clase dominante a aquella sin grado de filiación ni definición ritual (posiblemente extranjeros y/o cautivos), que no tendría derecho a incluir ajuar en su tumba, aunque nosotros sugerimos si ésta no se correspondería más con aquellos individuos sin posibilidad de acceder a una sepultura. Por tanto, si esto es lo que ocurre en el área argárica, la periferia parece imitar su "norma», aunque en una gradación menor.

Asimismo, algunos investigadores han planteado a lo largo del tiempo discusiones acerca de la importancia del metal en estos momentos. En relación con las creencias funerarias, podemos mencionar que los objetos elaborados con este material, y que ha sido incluidos en los enterramientos, constituyen una cantidad minoritaria en proporción con otros 
materiales, de más fácil elaboración y adquisición, como es la piedra, el hueso, la concha o la propia cerámica.

Esta circunstancia quizás se explique por la existencia de ciertos grupos que controlarian el beneficio del metal, al que no podrian tener acceso todos los individuos. Por tanto, formaría parte de los privilegios de unos pocos. Precisamente casi toda la producción de metal localizada en las sepulturas catalogadas de todo el Mediterráneo se destinó a fabricar preferentemente armas y adornos, indicadores de la capacidad de lucimiento y “riqueza» de los poderosos.

En esta situación, el acceso a la posesión de objetos metálicos parece configurarse como elemento diferenciador entre los individuos pudiendo destacar cuatro yacimientos del área argárica en función de sus peculiaridades: El Argar, El Oficio, Fuente Alamo y La Bastida de Totana (Murcia). Así, respecto a EL ARGAR, contamos con 254 enterramientos de los 559 catalogados que incluyen algún tipo de armas, concretamente cuchillos-puñales, hachas, alabardas y tres espadas, una proporción muy elevada aunque debemos tener en cuenta que faltan 421 sepulturas que no fueron incluidas por los Siret en su gran "corpus". Posiblemente se corresponden con tumbas sin ajuar o sólo con ofrendas cerámicas, que son las que prácticamente se encuentran ausentes en su documentación. La presencia de armas nos lleva a preguntarnos si estamos ante sepulturas de "guerreros", de individuos dedicados en vida a defender el poblado, convirtiéndose la espada en la máxima representación de ese control militar. Sin embargo, la diferenciación de grupo no sólo queda registrada en las ofrendas sino también en la tipologia de la tumba, ya que algunas cistas presentan un carácter "monumental", tanto en El Argar y en El Oficio como en Fuente Alamo.

Respecto al armamento metálico que incluyen, sólo podemos analizar catorce tumbas del total de doscientas de su necrópolis, que son las que individualizan los Siret. Doce de ellas incluian armas, por lo que esta "riqueza" en objetos de metal coincide con la importancia concedida en el poblado a la actividad metalúrgica. No debemos olvidar que precisamente aquí se halló un "altar de cuernos", empotrado además en el muro de una casa, reflejando por tanto, junto con el del Cerro de La Encantada (Ciudad Real), una ideología religiosa estable, ya representada en otros lugares del Mediterráneo Oriental.

En FUENTE ALAMO, los enterramientos muestran igualmente una relativa abundancia de armas, predominando los cuchillos-puñales. La única espada, frente a las tres encontradas en El Argar (con una mayor cantidad de sepulturas), nos permite incidir aún más en la presencia significativa de este tipo de objetos, quizá como reflejo de la necesidad de 
defenderse y, por tanto, de establecer una sociedad con carácter «militar». Asimismo, la espada puede ser también un simbolo de prestigio, aunque este criterio puede valer para otros objetos.

LA BASTIDA DE TOTANA (Murcia) se nos presenta igualmente como una "macronecrópolis". Sin embargo, a pesar de que en su poblado se encuentran restos materiales que cubren todo el proceso de trabajo metalúrgico, sus sepulturas incluyen una escasa cantidad de objetos metálicos, especialmente de armas. Nos encontramos asi con una desigualdad en los ajuares funerarios que quizás no esté indicando que era una minoría la que controlaba la actividad metalúrgica, ya que en este yacimiento se encontraron dos habitaciones dedicadas claramente a la producción de metal, debajo de las cuales se localizaron enterramientos, la mayoría infantiles con ajuar incluso metálico, caracteristica que los hace diferentes al resto, demostrando así la relación entre la actividad metalúrgica y la "riqueza" de ofrendas.

De cualquier manera, bien sea por el control de la metalurgia o por la apropiación del excedente, debió surgir una "élite" dentro ya de una incipiente sociedad compleja y estratificada, produciendose un cambio en los patrones de asentamiento y en los modelos económicos de explotación, tal como parecen reflejar los enterramientos, mientras otras zonas peninsulares no presentan las mismas respuestas, aunque la posibilidad de nuevos hallazgos nos pueda permitir ampliar el conocimiento de sus costumbres funerarias.

La utilización de armas como ofrendas funerarias en el Egeo y en el Próximo Oriente es igualmente significativa. Así, las espadas se encuentran bien representadas, ya que contamos con 22 tumbas que las incluyen, cistas y fosas preferentemente, aunque en la Peninsula se reparten entre cistas y "pithoi". El tipo de arma más abundante también es el cuchillo-puñal. Sin embargo, las tumbas orientales presentan un armamento más desarrollado.

Es decir, si consideramos que las necrópolis son un filtro ideológico de las creencias de una sociedad, y nos encontramos en relación con el Mediterráneo Oriental con una comunidad de intereses e ideas que concuerda con lo que ocurre en la Península, incluso en momentos anteriores con respecto a la situación peninsular, nos permitimos planear la posibilidad de la llegada de gentes de otros ámbitos del Mediterráneo como la consecuencia de ese movimiento económico $y$, por tanto, espiritual, que se observa en el II milenio a.C.

De cualquier manera, sea por un contacto accidental y recurrente o por una presencia mayor de gentes mediterráneas, el resultado fue una generalización de creencias espirituales, que no nos parece tan difícil de 
mantener si tenemos en cuenta que incluso en Anatolia ya se disponía de un barrio propio para los comerciantes asirios (el "Karum" de KaneshKültepe) como fruto del movimiento comercial que se desarrolló durante el Il milenio en el Mediterráneo. En esta situación no resulta tan inverosimil pensar que la circulación e intercambio de productos no llevará emparejada un movimiento de ideas religiosas, llegando a afectar a la Península Ibérica, al igual que sucedió con otras áreas europeas.

Por tanto, la introducción de un rito nuevo de enterramiento: la inhumación individual, se convierte en una práctica habitual incluso desde el III milenio en muchas regiones del Mediterráneo Oriental, encontrándose también analogías con la Península Ibérica no sólo en la tipología del enterramiento sino en la localización de la tumba, la mayoría intramuros e incluso en el interior de las viviendas o asociado a templos, quizás fruto de un "status" social o político.

Todos estos paralelismos en las prácticas funerarias de los dos ámbitos del Mediterráneo, a pesar de no contar aún con evidencias propiamente materiales, sugieren la existencia de relaciones más allá del plano espiritual, dentro de sociedades fuertemente jerarquizadas y más complejas, tal como queda reflejado en los ajuares funerarios y en la propia tipología de las tumbas, realizadas por los vivos en respuesta a unos convencionalismos que se manifiestan, aquí y ahora, en una desigualdad material y en unos ritos que carecen de tradición en la Península, aunque algunos investigadores puedan llegar a recordarnos la existencia de las sepulturas campaniformes, que, sin embargo, faltan en el Sureste, lugar de origen de la cultura argárica.

En definitiva, nos encontramos con la cristalización de unas costumbres funerarias ya existentes en otros lugares del Mediterráneo. Esperemos que nuevos datos nos permitan profundizar más en las creencias espirituales que se desarrollaron en este entorno durante el II milenio.

\section{BIBLIOGRAFIA}

AMO, M. DEL 1979: "Los ritos funerarios en los enterramientos en cista del Suroeste peninsular. Elemento determinante de una cultura", I Mesa redonda sobre a pré a protohistoria do Sudoeste peninsular. Setúbal-Palmela, págs. 24-35.

APARICIO, J. 1976: Estudio económico y social de la Edad del Bronce Valenciano. Valencia.

ARTEAGA, O. y SchubarT, H. 1981: "Fuente Alamo. Campaña de 1979", N.A.H., XI. Madrid, págs. 7-32.

AYALA, M. M. 1986: «La cultura de El Argar en Murcia. Datos actuales. Un avance para su estudio", Homenaje a Luis Siret. Madrid, págs. 329-340.

BALDOMro, A. y FeRRER, E. 1984: "Las necrópolis en cistas de la provincia de Málaga", C.P.U.G., 9. Granada, págs. 175-194 
Bernabo, L. 1953-54: "La Sicilia prehistórica y sus relaciones con Oriente y la Península Ibérica", Ampurias, XV-XVI. Barcelona, págs. 137-187.

- 1969: “Considerazioni sull'Eneolitico e sulla Prima Età del Bronzo della Sicilia e della Magna Grecia", Kokalos, XIV-XV. Palermo, págs. 20-59.

BlAnCE, B. 1964: “The Argaric Bronze Age in Iberia», Guimaraes, LXXIV, 1-2. Guimaraes, págs. 129-142.

Blasco, M. C. 1987: "El Bronce Medio y Final», Ciento treinta años de arqueologia madrileña, Madrid, págs. 83-108.

Bosch, P. 1932: "La Edad del Bronce en la Península Ibérica», Investigación y Progreso, 6. Madrid.

- 1954: "La Edad del Bronce en la Peninsula Ibérica», A.E.A., XXVII. Madrid, págs. 45-92.

BouzEK, J. 1985: "The Aegean Anatolia and Europe: Cultural interrelations in the second millennium B. C.", S.I.M.A., XXIX. Göteborg.

- 1985: "Relations between barbarian europe and the aegean civilizations", Advances in World Archaeology, 4. Londres, págs. 71-114.

CarRasco, J. 1979: “Algunas cuestiones acerca de la cultura argárica en la provincia de Granada", C.N.A., XV. Zaragoza, págs. 265-276.

CASKEY, J. L. 1966: "Greece and the Aegean islands in the Middle Bronce Age", Cambridge Ancient History, II, IV (a)/45. Cambridge.

Cipolloni, M. 1982: “Ambiente, economia e società dall'Eneolitico all'Età del Bronzo in Italia Sud-Orientale", Dialogui di Archeologia, 2. Roma, págs. 27-38.

- 1983: "Cist graves and chamber tombs", A.B.S.A., 78. Londres, págs. 55-67.

- 1986: “Early Mycenaean Greece and the Mediterranean”, Actas Traffici Micenei nel Mediterraneo. Taranto, págs. 271-276.

DOUMAS, CH.: "Early Bronze Age burial habits in the Cyclades", S.I.M.A., XLVIII, Göteborg.

Fernandez Vega, A. 1986: La Edad del Bronce en el Pais Valenciano. Madrid.

Gil-Mascarell, M. y Enguix, R. 1986: "La cultura del Bronce Valenciano": Estado actual de la investigación", Homenaje a Luis Siret. Madrid, págs. 418-424.

GIL PulIDo, J. I. et alii, 1988: “Excavaciones en el yacimiento del Bronce Medio del Cerro del Obispo. Castillo de Bayuela (Toledo)", Actas I Congreso de Historia de CastillaLa Mancha. Ciudad Real, págs. 93-100.

Gilman, A. 1976: “Bronze Age dynamics in southeast Spain», Dialektical Anthropology, 1. Amsterdam, págs. 307-319.

- 1981: "The Development of social stratification in Bronze Age Europe", Current Anthropology, 22, 1. Chicago, págs. 1-23.

HÄGG, R. y NORDQUiST, G. C. 1990: "Celebrations of death and divinity in the Bronze Age Argolid", Acta Instituti Atheniensis Regni Sueciae, XL. Estocolmo.

JIMENO, A. 1983: "Nuevas bases para el estudio de la Edad del Bronce en la zona oriental de la Meseta Superior", C.N.A., XVI. Zaragoza, págs. 309-320.

LULL, V. 1983: La cultura de El Argar. Madrid.

Martín Robles, C. et alii, 1983: “The Bronze Age of La Mancha", Antiquity, 67, 254. Cambridge, págs. 23-45.

Martinez Santaolal_a, J. et alii 1947: “Excavaciones en la ciudad del Bronce Mediterráneo II, de La Bastida de Totana (Murcia)", I.M.C.G.E.A., 16. Madrid.

MATA, J. DE 1963: La Edad del Bronce, Historia de España (director R. Menéndez Pidal), I. Madrid, págs. 755-852.

Montero, I. 1992: "La actividad metalúrgica en la Edad del Bronce del Sudeste de la Península Ibérica: Tecnologia e interpretación", T.P., 49. Madrid, págs. 189-215.

MYLONAS, G. E. 1951; The cult of the death in helladic times. Washington.

Nieto, G. y SÁnChez MESEgueR, J. 1988: “Bases para la sistematización del estudio de la Edad del Bronce de La Mancha", Actas / Congreso de Historia de Castilla-La Mancha, II. Ciudad Real, págs. 221-227.

Nieto, G. et alii 1983: “El Cerro de La Encantada (Granátula de Calatrava). Campaña de 1979", N.A.H., XCll. Madrid, págs. 7-41.

Nordquist, G. C. 1990: "Middle Helladic burial rites: Some speculations", Acta Instituti Atheniensis Regni Sueciae, XL. Estocolmo, págs. 35-43. 
OVerbeCK, G. F. 1975: Graves and burial. Customs at Ayia Irini, Kea. Michigan.

PELON, O. 1976: Tholoi, Tumuli et cercles funeraires sur les monuments funeraires de plan circulaire dans l'Egée de l'Áuge du Bronze (III et II. millenaires av. J. C.). Atenas.

Peron, R. 1971: L'Età del Bronzo nella Penisola Italiana. Florencia.

POYATO, C. 1991: "Aplicación de las bases de datos a las necrópolis del Minoico Reciente en el área de Knossos", Congreso Internacional de Micenologia, II. Roma-Nápoles.

Poyato, C. y VÁzquez, A. M. 1988: “El segundo milenio a.C. Una época de "cambio" en el Mediterráneo: Las prácticas funerarias", Espacio, Tiempo y Forma, II, 1. Madrid, págs. 15-43.

SÁnCHEZ Meseguer, J. et alii 1983: “El Oficio y La Encantada: Dos ejemplos de culto en la Edad del Bronce en la Península Ibérica", C.N.A., XVI. Zaragoza, págs. 383-395.

- 1985: "El altar de cuernos de La Encantada yu sus paralelos orientales", Oretum, I. Ciudad Real, págs. 125-167.

SchuBART, H. 1974: "La cultura del Bronce en el Sudoeste peninsular. Distribución y definición", Miscelánea Arqueológica, II. Barcelona.

- 1976: "Relaciones mediterráneas de la cultura de El Argar», Zephyrys, XXVI. Salamanca, págs. 331-342.

SchuBART, H. y ARTEAGA, O. 1986: "Fundamentos arqueológicos para el estudio socioeconómico y cultural del Área de El Argar", Homenaje a Luis Siret. Madrid, págs. 289-307.

Seferiades, M. Troie I. Materiaux pour l'étude des societés du nord-est egéen au début du Bronze Ancien. Paris 1985.

SIRET, E. y L. 1980: Las primeras Edades del Metal en el Sudeste de España. Resultados obtenidos en las excavaciones hechas por los autores desde 1881 a 1887. Barcelona.

STECH, T. 1974: “Early Bronze Age burial customs in Western Anatolia", A.J.A., 78. Boston.

Stos-Gale, Z. A. y GALE, N. H. 1990: "The role of Thera in Bronze Age trade in metals", Thera and the Aegean world III, I. Londres, págs. 72-92.

Treull, R. et alli 1989: Les civilisations égénnes du Néolithique et de l'Age du Bronze, Paris.

VALIENTE, J. 1987: “Enterramientos de rito argárico en la Meseta. El poblado de La Loma del Lomo (Cogolludo, Guadalajara)", Revista de Arqueologia, 73. Madrid, págs. 34-43.

WACE, A. J. B. et alii 1979; "Excavations at Mycenae, 1939-1955", A.B.S.A., 45-56. Oxford.

\section{ABREVIATURAS}

A.B.S.A. Annual of the British School at Athens.

A.J.A.

C.N.A.

N.A.H.

S.I.M.A.

T.P.

American Journal of Archaeology.

Congreso Nacional de Arqueología.

Noticiario Arqueológico Hispánico.

Studies in Mediterranean Archaeology.

Trabajos de Prehistoria. 